\title{
“Rrojta veç të lë një këngë! Rrojta veç të lë një vepër!,,
}

Astrit Bishqemi

Kushtuar shkrimtarit Hyjni Ceka (6 tetor $1932-20$ gusht 2019)

1

Këto javë u shua dhe na la shkrimtari elbasanas, Hyjni Ceka. Përcjelljen me nderime e meritonte se qe një krijues me shumë përmasa. Dhe unë këtu do të mundohem të skicoj disa nga ato.

Përmasa e parë e karakterit të tij qe ajo njerëzore, humane.

E njihja Hyjniun prej kohësh. Dhe më ka lënë mbresa komunikimi i tij me të tjerët; komunikim i thjeshtë, i përzemërt, i çiltër. Veç jo me çfarëdolloj njerëzish...

E kam parë në shkollë si mësues, po edhe tek drejtonte rrethin letrar në ishShtëpinë e Pionierit (sot: Qendra Kulturore e Fëmijëve). Kurdoherë i afërt, komunikues, i përzemërt e tërë humor me fëmijët, sidomos me talentet letrare. Mundohej t'i njihte jo vetëm me emër, po edhe familjarisht, me prindër, me motra e vëllezër, me farë e me fis, me mësuesit që u jepnin mësim. Kjo ishte rruga e tij për në zemrën e fëmijës, vajzë qoftë apo djalë, nga qyteti apo nga fshati. Pastaj, u takonte edhe prindërit, një e nga një dhe shtrohej miqësisht me ta në biseda. "E di që ke një vajzë të talentuar?- i thoshte. -Duhet të përkujdesesh për të...”. Kurse vetë Hyjniu për çdo krijim të ri të letrarit, gëzohej e gëzohej vetë si fëmijë, ia ngrinte në qiell dhe mundohej t'ia publikonte, sa duke e recituar në shkollë, sa duke e botuar në gazetën e rrethit, në gazetat e revistat qendrore për fëmijë, duke e transmetuar në radio ose në televizor. 


\section{Albanon}

\section{Revistë kulturore}

Dhe mendoni, se ishte pikërisht ai Hyjni, që me ne, krijuesit e rritur, sillej shumë qibar e nazik, nuk parapëlqente lehtë asgjë dhe na godiste me sëpatën e dardharit:

- Jo, jo, duhet ta punosh ende. Duhet të lexosh më shumë, të përpiqesh më tepër.

Më tej na sillte shembuj nga jeta e vet.

- E di si më ka thënë njëherë Jakov Xoxa, kur drejtonte Faqen Letrare të gazetës Zëri i Rinisë? „Duhet të luftosh për ta ngritur kulturën tënde, Hyjni. Se lexuesit e tu do të thonë: "Hë, more, nga ky që s'ka kulturë për vete do të mësojmë ne?”

Dhe miku ynë përfundonte duke na thënë:

- E, pra, kur s'ke vetë në kokë, kur nuk je i ditur e i kulturuar, nuk ke ç‘i jep lexuesit.

Veç ishte i afërt me ne, me të gjithë krijuesit. Një kolegut të tij, krijues i nderuar, që jetonte në Tiranë, për çdo 14 mars, i dërgonte jo ballakumet e ëmbla të Elbasanit, por një tufë karakafte e menekshe erëkëndshme të ullishtës, se e dinte që tjetri i kishte dobësi ato, i dërgonte një copëz të vendlindjes, së bashku me zemrën e mikut.

Miqësia e zemërata e tij ishin proverbiale. Kohët e fundit, disa herë në ditë, do të na merrte në celular ne, disa krijuesve që na kishte më për zemër. Prisheshe përgjithnjë me të, fjalavjen, po t’i gjeje ndonjë cen krijuesit e studiuesit elbasanas, Dhimitër Shuteriqi. Miqësia me dy Bujarët i ishte ngulitur në zemër e në shpirt. S'dëgjonte kurrsesi të botonte në vend tjetër veç "Onufrit", me president Bujar Hudhrin. Gjithashtu, s'dëgjonte kurrsesi të braktiste kopertinën e bukur me portretin e Kristoforidhit, që i pati kompozuar artisti Bujar Kapllani (nëntë libra të tij janë me këtë mbulesë të njëjtë).

Duke i trajtuar kështu njerëzit, Hyjniu pati dhjetëra e dhjetëra miq, me të cilët shtrohej në biseda të thjeshta, duke vjelur e përvetësuar nga ata përvoja të ndryshme jetësore, të cilat janë aq të nevojshme e të domosdoshme për një krijues.

\section{2}

Përmasa e dytë, është ajo kulturore.

Kurdoherë në jetë ai qe munduar, për vete, në radhë të parë, ta zbatonte porosinë e mjeshtrit Jakov Xoxa, pedagogut të shkencës së letërsisë. Me një 
copë shkollë pedagogjike, siç shprehej vetë, mësuesinë e ushtroi ku qe më larg e më vështirë, mes Labërisë e thellë fshatrave të Kavajës, përpara se të sistemohej në Shkollën e Mesme Bujqësore të Cërrikut e në shkollat e qytetit të lindjes, ku edhe doli në pension. Por në ato zona të thella, të largëta e të vështira, Hyjniu nuk ra në pesimizën, nuk iu vu rakisë, po diturisë. Kohën e lirë, që e kishte me pash, ia përkushtoi ngritjes së vet arsimore e kulturore. Pa shkëputje nga puna e mbaroi universitetin. Gjithashtu, atje ku ishte, nuk bënte jetë të mbyllur, por takohej me njerëz të thjeshtë dhe bisedonte shtruar, merrte pjesë në gëzimet e hidhërimet e tyre, dëgjonte me vëmendje, mbante shënim ngjarje, tipa, fjalë të urta e të rralla, këngë e gojëdhëna. Kështu mundi të bëhej njohës i mirë i traditave kulturore dhe i krijimtarisë gojore, i prozës popullore edhe i atyre trevave e jo vetëm i Shqipërisë së Mesme.

Mjedisi i ngritur kulturor familjar i Hyjniut ndikoi shumë në përgatitjen dhe formimin e këtij njeriu.

Se Hyjniu rridhte prej një dere ku të gjithë u përfshinë në luftën për pavarësi. Se Hyjniu pati gjysh nga nëna Hysen Xhanin, pjesëmarrës në lëvizjen antiosmane...

Se Hyjniu pati baba Salim Cekën, një intelektual që punoi rreth pesëmbëdhjetë vjet me përkthimin e eseve të Shopenhaurit dhe shtëpinë e vet e pati bërë sofër ku mblidhte intelektualët krijues të Elbasanit. (Dhe ai baba u dënua me vdekje pikërisht për këtë arsye, meqë përkthente atë filozof „rreaksionar“ e jo Marksin...).

Se Hyjniu pati njohje nga afër me rilindas të tillë, si: Lef Nosi, Sotir Kolea e Milto Sotir Gurra.

Se Hyjniu edhe pas Luftës Antifashiste pati pjesëmarrje aktive në Lëvizjen Letrare, duke bashkëpunuar me Dhimitër Shuteriqin, Sterio Spassen, Llazar Siliqin, Enver Ficon, Dritëro Agollin, Ismail Kadarenë, Fatos Arapin, Nasho Jorgaqin, Fadil Krajën etj.

Por edhe tipi i Hyjniut vetë qe faktori kryesor. Fara binte në tokë të shëndetshme dhe hidhte rrënjë. Për ngritjen e vet kulturore Hyjniu i dha rëndësi edhe asaj mënyre që në gjuhën popullore ne e cilësojmë me fjalët „,me të vjedhur“", ashtu sikurse çiraku e merr zanatin nga mjeshtri i vet. Për këtë, le të sjellim si argument atë pasazhin që përshkruan vetë në shkrimin Rapsodi hungareze. Kur shkonte në Tiranë për të dhënë provimet e korrespondencës dhe bujtëte në shtëpinë e ungjit, arkeologut dijetar, Hasan Ceka, në dhomën e bibliotekës ku i shtronin për të fjetur, ngrihej natën dhe shfletonte e shijonte mrekullitë e atyre volumeve... 


\section{Albanon}

\section{Revistë kulturore}

Ja pra, në këtë mënyrë i ngriti Hyjniu dijenitë e tij dhe u bë nga njerëzit më të kulturuar të qytetit tonë e më gjerë. Falë kujtesës së vet të përsosur, me Hyjniun mund të uleshe e të diskutoje për njerëz e për ngjarje të ndryshme të trevës sonë, për zakone e tradita; ai të këndonte këngë e të recitonte qindra vargje popullore. Rrezaton kjo njohje e kjo dije, kjo kulturë e gjerë në tërë krijimtarinë e tij letrare. Se studimin e përshkrimin për Ditën e Verës, në vëllimin me të njëjtin titull, vetëm një njeri me dijet e Hyjniut mund të na e dhuronte. Se shkrimi, Rinia e Hasan Cekës, që i ngre monument protagonistit, rrezaton informacionin e gjerë e të saktë shkencor të shkrimtarit. Se në shkrimin-portret për Gani Daiun, mjeshtrin shqiptar të didaktikës, edhe autori del mjeshtër i mësimdhënies, njohës i metodave bashkëkohore, si dhe vlerësues i asaj çka ishte më pozitive në metodat që përdorte protagonisti i shkrimit.

Ndaj, si përfundim, edhe unë e quaja Hyjniun “enciklopedi e gjallë” e qytetit tim.

\section{3.}

Përmasa e tretë dhe më kryesorja, është ajo e krijuesit të talentuar.

Qysh gjatë kohës së Luftës, nxënësi Hyjni Ceka filloi të thurte vargjet e para fëminore, nën kujdesin e mësuesve të tij Qamil Guranjaku e Gani Daiu. Gjatë atyre viteve të nxehta, vjershat e Hyjniut qarkullonin në grupet edukative. Ishin vjersha që lidheshin me ngjarje të kohës, që godisnin ndërrimin e posteve të qeverive. Pas qeverisë së Vërlacit erdhi ajo e Mustafa Krujës dhe pas saj, ajo e Eqrem bej Libohovës. Ja dhe vargjet fëminore me temë politike të Hyjniut:

Eqrem beu na ishte ndërrue

ke Parjami don me shkue,

ke Parjami n'kabinet

me na rrejtë gjith kët milet.

Ke Parjami kur na shkoi

dorën nalt se çna e çoi

dhe thërriti: "Re a noi!"

Fill pas mbarimit të Luftës, Hyjniun, ende 12-vjeçar, e shohim redaktor të revistës për fëmijë, "Zani i Pionierit”, që nxirrte atëherë Shtëpia e Rinisë në Elbasan dhe e shumëfishonte me shaptilograf. Në atë revistë gjejmë të botuar edhe vjershën e parë të Hyjniut, në numrin e muajtit qershor 1945. Titullohet Mentari: 


\begin{abstract}
Ditë e bukur, ditë pazari, njani shet e tjetri blen, se çna paska ky Mentari njiher' ikën, njiher'vjen, njiher' matet, njiher' ikën, nji gja do ai me ba, po se kujt ia paska frikën ky Mentari budalla.
\end{abstract}

Dhe më tej, vjersha tregon sesi fëmijët nxorrën roje të tyret, të cilët e kapën rrugaçin Mentar (emër i identifikuar) dhe bënë të ndërronte rrugë.

Vjersha tjetër e botuar po në këtë organ, në mars 1946, është një krijim intim i ndjerë, ku spikat naiviteti fëminor, kushtuar kujtimit të dhimbshëm të nënës, njeriut më të dashur për cilindo:

Tri vjet u banë

që kur m'ke lanë,

e dashun nanë.

Dhe tue qamë

un' tash po rri

se m'ike ti!.

Pa kamb'të isha

edhe pa sy

veç ty të kishja...

o nan' veç ty!

Dhe ndonjiherë

kur të kujtoj,

o nan'e mjerë,

për ty vajtoj....

E mandej iki

humb në mendime,

o nana ime...

Poezia entuziazmoi mësuesin e Hyjniut, poetin e mirënjohur, Ethem Haxhiademi, i cili, kur e lexoi, thirri: "Lum se ç‘djalë ka Salim Ceka!"

Këto ishin, pra, fillimet në udhën e vështirë letrare të Hyjniut. Dhe ai nuk reshti kurrë më. Ka aq dekada, që emri i këtij krijuesi qe i pranishëm sa në shkrime publicistike, ashtu dhe në krijime poetike e në prozë letrare. Për fëmijë e për të rritur. 


\section{Albanon}

Revistë kulturore

\section{4 .}

Shkrimtari, Hyjni Ceka, dha ndihmesë të veçantë në lëvrimin e tregimit për lexuesit e moshës së rritur shkollore. Në tri vëllimet e para të botuara prej tij (Horizonte të elektrifikuara - 1969, Muzika e jetës - 1973 dhe Gëzimi i motrave -1978), vihet re se fabulat janë të qëlluara. Gjithnjë te ky autor do të gjesh jo atë që është e zakonshme, por atë që është e veçantë në jetën e personazheve, duke krijuar përshtypjen se autori qëmtonte shumë në dukuritë e jetës. Tregimet më të mira të tij kanë realizim dinjitoz letrar. Narracioni i Hyjniut, siç ka vënë në dukje edhe kritika e kohës, është i shtrirë, i shtruar e i qetë, fraza është e punuar, e kujdesur, e qëndisur, fjalia - e menduar, kështu që shprehja apo frazeologjia e jep saktë e me ndjenjë mendimin që kërkon të transmetojë shkrimtari. Ky narracion është i përafërt me mënyrën popullore të të rrëfyerit. Disa nga karakteristikat e prozës së Cekës u vunë re qysh në vëllimin e parë me tregime. Kështu, te Mërkur Panxhi, autori ka arritur të skalitë bukur njeriun e thjeshtë, të zgjuar e trim, të gatshëm për t t'u sakrifikuar për atdheun. Ngjarja është e besueshme dhe me forcë të ndjerë komunikuese. Tregimi Horizonte të elektrifikuara, që i fal titullin vëllimit të parë, vizaton në mënyrë realiste jetën e rëndë të fshatit dhe banorëve të tij në të kaluarën, gjë që jepet nëpëmjet zhgënjimit të një fëmije, i cili ndryshe e përfytyronte dhe ndryshe e gjeti fshatin.

Në shumë krijime të Hyjni Cekës, shpaloset lufta e fëmijëve kundër pushtuesve fashistë gjatë Luftës Antifashiste. Të tilla janë tregimet: Për një ballë fishekë, Mbas demostrate, Tik Fishnjarri etj. Ato janë shkruar ngrohtë, rrjedhshëm e me fjalor të pasur. Psikologjia e fëmijëve të kohës jepet me mjeshtëri.

Dhe neve, sinqerisht na vjen keq që Hyjniu paskëtaj iu largua lexuesve të moshës së njomë në krijimtarinë e vet letrare... Ai kishte dashur të botonte për të rritur qysh në fazën e parë të krijimtarisë së tij, por nuk ia kishte arritur. "Në shtëpinë botuese $N$. Frashëri mua nuk më lejuan të hyja nga dera,- thoshte,- ndaj u futa nga dritaret e saj..."

\section{$5 \cdot$}

Jeta dhe krijimtaria e këtij shkrimtari shtrihet në dy kohë: në monizëm dhe në demokraci. Në të dyja ato periudha, përjetoi veçanërisht, dy ngjarje të rënda, që lanë gjurmë dhe e lënduan rëndë. 
Në të parën iu desh të ftohej me të atin, Salimin e burgosur. Dikur, adoleshent, në sallën e gjyqit, pati thirrur fort kundër trupit gjykues, kur të pandehurin e cilësuan tradhtar: “Jo, babi im nuk është tradhtar!". Por në çast, policët e kapën dhe e nxorrën jashtë zvarrë e me shqelma. E njohu kësisoj dhunën e diktaturës, ndaj vuri mend dhe ndërroi sjellje, u distancua nga i ati. Këtë e bëri për dy arsye: për arsimimin dhe të ardhmen e dy fëmijëve të tij Luljetës e Taulantit; së dyti, për letërsinë, që të mos i hiqej e drejta e botimit. Ky "mohim" qe sa për sy e faqe, se për të atin dhe veprimtarinë e tij kishte respekt e dashuri. Kam shkruar e botuar një portet për Salim Cekën, si një vlerë të anatemuar dhe këtë e pata bërë nën ndikimin e vlerësimin e Hyjniut, duke dëgjuar herë pas here kallëzimet e tij për të atin, tek na fliste me dashuri e krenari të veçantë...

Në periudhën e tranzicionit demokratik "telashin” e pati dhuratë nga letërsia e publicistika. Lum e shyqyr që i erdhi dita të kritikonte e t’ia hiqte petët lakrorit të sistemit diktatorial, filloi të nxirrte dufin e vet, të shkruante e të kritikonte me emër e me mbiemër persona të identifikuar të pushtetit e të partisë moniste. Por ndonjëri prej tyre, edhe pse mund të mos jetonte më, kishte lënë pas djemtë "azganë”, të cilët qenë bërë tashmë politikanë apo bisnesmenë të zot dhe dinin si ta vërtisnin rrotën. E hodhën në gjyq artikullshkruesin dhe "ia ndreqën paq kurrizin”. Gjyq i turpshëm i drejtësisë sonë, që zgjati muaj e vite dhe e stresoi shkrimtarin...

\section{6.}

Kohët e ndryshimeve të mëdha shoqërore, Hyjni Ceka qe edhe më prodhimtar. Se ai e konsideronte letërsinë si një instrument alarmi. Ai mendonte se syçeltësia, vetëdija, të qënit i ndërgjegjshëm për atë që ndodh me ty dhe rreth teje ishte njëra nga cilësitë kryesore të pjekurisë së një individi apo të një shoqërie... Se popujt e vetëdijshëm, sensorët alarmues i kanë shumë të përparuar, reagojnë në shenjat e para të rrezikut, sado të vogla qofshin dhe nuk pushojnë së alarmuari derisa nuk mënjanohet rreziku... Se organizmat që kanë defekt në sistemin alarmues-sinjalizues, nuk janë në gjendje të mbrohen dhe sëmuren rëndë etj. etj...

Pikërisht duke patur për prirje këto mendësi, në dhjetëvjeçarët e demokracisë, Hyjniu na dhuroi njëmbëdhjetë vepra të tjera dinjitoze, drejtuar lexuesve të rritur (hynte nga "dera" e shtëpive botuese tani e jo nga "dritarja"). Përfshihen këtu vëllime me biografi të letrarizuara, me tregime dhe ese, si: Tempuj dhe apostuj (1996), Dita e Verës (2000), Shenjtorë e djaj (2000), Valezakja 


\section{Albanon}

Revistë kulturore

(2005), Lule më lule e këngë më këngë (2007), Nëpër mite s’ka parajsë (2011), Mos ma harroni këngën (2015); vëllimet poetike të titulluara: Djemërishte dhe pleqërishte (1999), Divani i dimrit të fundit (2003), Sokëllet Karaburuni (2006), si dhe romani Mihal Shahini dhe të bijtë (2003). Pas kësaj Hyjniu iu vu rishikimit dhe publikimit cilësor të veprës së vet në "Onufri”, siç thamë, me përkujdesjen dashamirëse të botuesit, Bujar Hudhri. Në vitet 2017 dhe, 18 mundi të botonte në këtë kolanë vetëm dy veprat e para. Botimi i mrekullueshëm e bënte t'i ndrisnin sytë. "Unë jetoj si jevg, por botoj si mbret" shprehej.

Janë botime të arritura me një punë sistematike, të përkushtuar e të mundimshme. Janë vëllime të botuara me sakrifica (M'u drodh zemra kur më tregoi me ç'mjete po e botonte një vëllim të ri të radhës. Ishte detyruar të përdorte një grusht para, të cilat kish mundur t'i vinte mënjanë, që t' $\mathrm{i}$ gjindeshin për varrimin e vet). Janë vëllime të botuara me kërkesa të mëdha ndaj cilësisë artistike. (Mbaj mend njëherë që kishte ndenjur dy ditë mbi një tregim, por përsëri e kishte grisur, se nuk i dukej i arrirë, fraza i kishte tingëlluar e rëndomtë e joartistike). Janë vëllime të botuara me kërkesa edhe ndaj paraqitjes (Kërkoi t‘ua zhvoshknin mbulesën njëmijë kopjeve të vëllimit të përfunduar, në shtëpinë botuese "Nereida", t'ia shtypnin më cilësisht e t'ia vendosnin rishtazi. Dhe ashtu u bë.).

Në tërë këto vëllime, në përmbajtje, vëren një të vërtetë të lavdërueshme. Talentin krijues, artin e vet autori e ka vënë në shërbim të kohës së re, të tranzicionit politik, të demokracisë. Me pasion e mjeshtëri të rrallë, me ndjeshmërinë e një zemre të ndrydhur, na ndriçohen figura të ndritshme kombëtare të arsimit e të kulturës, të politikës, të nëpërkëmbura ose të mohuara fare, të përndjekura e të persekutuara nga sistemi i kaluar diktatorial. $\mathrm{Na}$ ndriçohen shkrimtarë si Haxhiademi, Lef Nosi, Filip Papajani e Kin Dushi, politikanë si Qamil Çelirama, albanologë si Franc Nopça, Edith Durhami e Margaret Hazllëku, arsimtarë si Apostol Gega, klerikë si Papa Jorgji Theohari, patriotë si Sulë Domi, familje patriote si ajo e Xhanëve; artistë si tenori Kristaq Antoniu që në Itali më 1937-n, në konkursin e këngës qytetare të Vendeve Mesdhetare, këndoi me mjeshtëri serenatën e hershme shqiptare "As-aman o syri $i$ zi”, të krijuar gati dy shekuj më parë nga Ashik Korçari etj. etj.

Stili i këtij shkrimtari është i veçantë. Me fjali të shkurtra, me plot presje, me pika retiçence më shumë. Lexuesit i jepet mundësia të pushojë një grimë, e çlodh ky stil, por e bën edhe ta ripërtypë fjalën a fjalinë, ta rimendojë 
shprehjen, ta kapë mirë nëntekstin e saj, të meditojë. Kemi aty elbasanasin, po edhe diçka nga Kuteli i madh dhe nga Shuteriqi patriark i tregimit dhe i studimeve elbasanase. Veç gjithësesi, stil i veçantë, vetiak, origjinal, me taban elbasanishten letrare.

Letërsia e Hyjniut, krijimet e tij janë realiste. Autori nuk i bën thirrje aq imagjinatës sesa kujtesës. Tregimet e tij në njëfarë mënyre janë të përjetuara. Një ngjarje e jetës, që i ka lënë mbresa të pashlyeshme, tipa e karaktere reale, të identifikuar ngrihen, tipizohen e përgjithësohen në art.

Edhe peizazhi i këtij autori është i ndjerë. Njëri, më tregonte njëherë sesi e kishte parë Hyjniun një pasdite në Shpat, në Liqenin e Gjinarit - Bukanik, të rrëmbyer nga bukuria e perëndimit të diellit. Dhe pasi dielli qe rrëzuar përtej, shkrimtari kishte nxjerrë bllokun e shënimeve dhe kishte zënë të hedhë mbresat e përjetuara atë çast, peizazhin konkret. Si ai piktori që bën etyde të ndryshme për t'i përdorur më vonë në kompozimet e veta.

\section{7.}

Mund të përmendnim edhe faktin që ky krijues është mohues në shumëçka për vitet e demokracisë, se pena e tij, si shpatë e mprehtë tringëllinte e priste me duf sa majtas aq edhe djathtas, pozitë e opozitë. Personalisht mund të mos jem dakord me këtë mendësi, me ndonjë epitet që autori i vishte $\mathrm{X}$ figure të politikës sonë etj. etj. Mund të mos pajtoheshim, pra, me këtë nihilizëm të Hyjniut. Por, le t'i lëmë debatet për në një diskutim krijues më të gjerë të veprës së këtij autori. Dhe të vazhdojmë në skicimin tonë.

...Përmasa e katër është ajo e një veprimtari aktiv.

Sidomos kjo përmasë doli më në pah viteve të tranzicionit demokratik. Hyjni Ceka, u shqua si intelektual me guxim të gjallë qytetar, jo vetëm i penës, po edhe i tribunës, edhe i ekranit. Në tubime të ndryshme demokratike salla pati jehuar nga zëri i tij i fuqishëm, që ndriçonte me art, pasion e ndjeshmëri figura iluministësh të mohuara. Ai nuk e lexonte kumtesën e përgatitur vetë, por e interpretonte; më tepër se aq, e përjetonte atë që kishte shkruar... Se i kishte buruar jo nga truri, po nga zemra, nga gjaku rebel. Ndaj edhe ndizej horë dhe e bënte për vete dëgjuesin. Kam qenë vetë i pranishëm, si është ngritur dhe e ka duartrokitur e tërë salla e Shtëpisë së Kulturës Elbasan në kumtesën e mbajtur për Qamil Çeliramën, salla e shkollës së mesme pedagogjike "Luigj Gurakuqi”, në kumtesën që Hyjniu mbajti për Apostol Gegën etj. 


\section{Albanon}

Revistë kulturore

\section{8.}

Po në këtë përmasë të veprimtarit aktiv do të shtoja një tjetër përmasë të karakterit të tij, atë idhnake apo ndonjë cen tjetër.

Se Hyjniu qe edhe një zemërak e idhnak i idhët.

Mbaj mend sesi qe grindur njëkohë me redaktoren e Shtëpisë Botuese "Naim Frashëri” për një frazë. Ishte një urim i thukët që mjeshtri i fjalës e kishte përqokur nga goja e nënave të trevës sonë, po që ia kishin sakatosur në botimin e librit "Horizonte...”. Në dorëshkrim nëna fshatare e përkëdhelte të birin, në mos gabohem, me urimin "Oj rrite!... oj fale!...". Por kush do ta rriste e kush do ta falte? Ideologjia komuniste nuk pranonte Perëndinë, por Partinë. Ndaj edhe redaktorja ia kishte ndryshuar: "Oj, m’u rritsh! Oj m‘u rritsh!”

Vitet, mosha nuk ia flashkëzuan zemrën Hyjniut, por e bënë më fshikullues ndaj së keqes shoqërore, më inatçi e më shpërthyes.

Ai goditi me forcë shumë dukuri negative të tranzicionit. Foli e kritikoi me afsh e me gjongël aspekte konkrete, persona konkretë. Hyjniu nuk të falte. Pena e tij nuk njihte kë vinte në shënjestër: avokatë e noterë, garipë e sekserë, ish-sekretarë partie, prefektë e deputetë. Qe stigmatizues, goditës sarkastik, përçmues, asgjësues. E denoncoi edhe në vargje të keqen dhe e luftoi atë njëqindfish më fort sesa mund ta arrinte një tjetër me forma të tjera. Janë bërë popullore vargjet e tij të tilla si:

Se ky popull sështë në vete

që zgjedh X-en deputete.

Dhe X-ia qe person i identifikuar i Elbasanit.

Vënien në majë të bodecit me bejte humoristike e pati pasion që i zgjati për tërë jetën.

Në vrullin kritikues, rrezik t'ia thyente mbi kokë ndonjë të pafytyri bastunin që mbante në dorë vitet e fundit!

9.

Nuk po zgjatem më në përmasa të tjera si ajo e dashurisë për trevat shqiptare jashtë kufirit shtetëror etj. etj.

Më lejoni të përmend vetëm faktin që kur krijuesi Hyjni Ceka festoi 70-vjetorin e lindjes, thurte këto vargje për jetën e tij:

Ja ku jam në shtatëdhjetë vite, pata nerva prej çeliku... 
Po, qe një jetë e tërë e rropatur dhe e rrekur rreth shkrimeve. Dhe jetëgjatësinë, krijuesi ia diti për hak veç talentit të vet, që e mbajti gjallë dhe e bëri të mbijetojë. Talentit, asaj dhuntie të perëndishme, asaj i falej edhe në ditët e pleqërisë. Ndaj edhe këndonte me duf:

Rrojta veç të lë një këngë!

Rrojta veç të lë një vepër!

Nuk njoh krijues tjetër që të ketë shtënë aq shumë vlerësim e aq shumë dashuri me veprën e vet sa Hyjniu. Ndoshta e tejkalonte masën. E nderonte dhe i përfalej talentit të vet duke e animizuar dhe duke e personifikuar atë si njerëzit herakë. Natën e Vitit të Ri, i rendiste varg e vistër në këmbë, mbi syprinën e tryezës librat e vet, u gëzohej si fëmijë dhe e cakronte si dollibash me ta gotën e verës. I uronte të shtoheshin e të jetonin sa më gjatë.

Muajt e fundit, shkoja shpesh me shokë letrarë te Hyjniu. Me Dhimo Tarushën, me Çim Gegën, me Ahmet Mehmetin, me atë Stavri Çipin... në apartamentin e vet, në spital, në shtëpinë e së bijës ku dhe mbylli sytë. Në shtratin e lëngimit mund të shikoje ndonjë skenë të ngjashme, ca si qesharake, që përgjatë dhimbjes ndaj kolegut e mikut të moshuar që po largohej nga kjo jetë, të provokonte një gaz të lehtë nën buzë; i shtrirë në kurriz, mbi gjoks mbante dy nga librat e tij, botime speciale, me kapakë të trashë. Ata i ngriheshin e i uleshin ritmikisht ngadalë.

- Po hiqjani ata libra, se i rëndojnë dhe ia vështirësojnë frymëmarrjen,sugjeroi Dhimoja.

Luljeta, bija e dhembshur që u përgjërua ditë e natë në krye të atit, çoi lehtë në gaz buzën e trishtuar:

- Jo, e kemi provuar; e ndjen menjëherë dhe na gërthet. Ata i japin gajret dhe e mbajnë gjallë.

Po, librat, letërsia e mbajti gjallë, i zgjati jetën Hyjniut. Mbylli sytë me një ëndërr të bukur dhe me një peng: deshi ta botonte tërë veprën e vet në një kolanë luksoze, por nuk ia arriti. Veç edhe me aq sa bëri, ai i la letërsisë shqiptare disa krijime antologike. Pa le Elbasanit. Dhe e meriton plotësisht vlerësimin e kolegut shkodran Fadil Kraja: "Hyjniu $i$ dha aq shumë Elbasanit dhe kërkoi aq pak prej tij..."

Të qoftë i lehtë dheu i vendlindjes, o miku ynë, i talentuari Hyjni, “aristokrati” nazik Hyjni, i pakënaquri e kërkuesi Hyjni, rebeli e idhnaku Hyjni!

2002, 2019 